\title{
Desenvolvimento e Avaliação de Coalhada (Com e Sem Adição de Lactobacillus Paracasei) Tipo Sunday com Mirtilo
}

\author{
Maria Eduarda Daussen Dutra (I), Deise Helena Baggio Ribeiro (I), \\ Ana Carolina Sampaio Doria Chaves (II), Daiane Aparecida Paggi \\ (I), Luiza Martins Reguse (I) \\ (I) UFSC - Universidade Federal de Santa Catarina (Rodovia Admar Gonzaga, 1346 - Itacorubi \\ Florianópolis - SC), (II) EMBRAPA - EMBRAPA (Rio de Janeiro)
}

\section{Resumo}

Com as tecnologias de comunicação e a globalização, aumentou a preocupação com uma alimentação mais saudável e neste contexto surgiram os alimentos funcionais. A coalhada é um tipo de leite fermentado com características similares as do iogurte, mudando as bactérias láticas adicionadas (Lactococcus lactis ssp. lactis e Lactococcus lactis ssp. cremoris) e a temperatura de fermentação $\left(37^{\circ} \mathrm{C}\right)$. Os leites fermentados têm sido cada vez mais consumidos devido ao sabor, odor e textura agradáveis e a aceitação destes produtos aumenta ainda mais quando são acrescidos de polpa ou preparados de frutas. $\mathrm{O}$ mirtilo é rico em compostos fenólicos como as antocianinas que agem como antioxidantes, sendo considerada a fruta da longevidade. Os leites fermentados são ótimos veículos para adição e consumo de culturas probióticas, que são microorganismos capazes de sobreviver a passagem pelo estomago, chegando ao cólon do intestino em concentrações elevadas com capacidade de colonizálo e melhorar o funcionamento do intestino. Neste trabalho foram desenvolvidas duas formulações de coalhada tipo Sunday com preparado de mirtilo, sendo uma formulação com adição da cultura probiótica Lactobacillus paracasei e a outra sem. Estas duas formulações foram avaliadas durante 14 dias de armazenamento refrigerado. Os resultados mostraram que características tais como: a umidade, $\mathrm{pH}$, acidez, conteúdo

\footnotetext{
Referência:

Maria Eduarda Daussen Dutra, Deise Helena Baggio Ribeiro, Ana Carolina Sampaio Doria Chaves, Daiane Aparecida Paggi, Luiza Martins Reguse.Desenvolvimento e Avaliação de Coalhada (Com e Sem Adição de Lactobacillus Paracasei) Tipo Sunday com Mirtilo. In: Anais do $12^{\circ}$ Congresso Latinoamericano de Microbiologia e Higiene de Alimentos - MICROAL 2014 [= Blucher Food Science Proceedings, num.1, vol.1]. São Paulo: Editora Blucher, 2014.

DOI 10.5151/foodsci-microal-018
} 
de lipídios e cinzas não foram significativamente $(\mathrm{p}>0,05)$ alteradas pela adição da cultura probiótica. A adição de Lactobacillus paracasei afetou significativamente $(\mathrm{p}<0,05)$ a sinerese (reduzindo) e o teor de proteína e de carboidratos (calculado por diferença). O preparado de mirtilo que foi utilizado no produto apresentou potencial de atividade antioxidante de $330,8 \mu \mathrm{mol}$ de TEAC e 36,65 mg de GAE, evidenciando que a adição desta fruta pode melhorar as características nutricionais do produto. A contagem de bactérias láticas permaneceu alta (>109 UFC/g) durante os 14 dias de armazenagem. A vida útil dos produtos foi limitada a 7 dias pela contagem de bolores e leveduras, cabe salientar que não foram adicionados conservadores químicos, que poderiam prolongar a vida útil destes produtos.

Palavras-Chave: Bactérias láticas, Coalhada, Mirtilo Agência de Fomento: 